\title{
An integrated population model for estimating the relative effects of natural and anthropogenic factors on a threatened population of Pacific trout
}

\author{
Mark D. Scheuerell ${ }^{1,5}$, Casey P. Ruff ${ }^{2}$, Joseph H. Anderson ${ }^{3}$, Eric M. Beamer ${ }^{4}$ \\ ${ }^{1}$ Fish Ecology Division, Northwest Fisheries Science Center, National Marine Fisheries Service, National \\ Oceanic and Atmospheric Administration, Seattle, WA USA, mark.scheuerell@noaa.gov \\ ${ }^{2}$ Skagit River System Cooperative, La Conner, WA USA, cruff@skagitcoop.org \\ ${ }^{3}$ Washington Department of Fish and Wildlife, Olympia, WA USA, joseph.anderson@dfw.wa.gov \\ ${ }^{4}$ Skagit River System Cooperative, La Conner, WA USA, ebeamer@skagitcoop.org \\ ${ }^{5}$ Present address: U.S. Geological Survey Washington Cooperative Fish and Wildlife Research Unit, \\ School of Aquatic and Fishery Sciences, University of Washington, Seattle, WA USA, scheuerl@uw.edu
}

Running title: Density dependent populations dynamics

Key words: density dependence, population dynamics, missing data, state-space, Bayesian, hierarchical, hatchery, Oncorhynchus

Number of words: 6971 (total); 310 (summary); 4670 (main text); 79 (acknowledgements); 1617

(references), 0 (tables); 295 (figure legends)

Number of tables: 0

Number of figures: 6

Number of references: 58

Corresponding author:

Mark D. Scheuerell

U.S. Geological Survey Washington Cooperative Fish and Wildlife Research Unit School of Aquatic and Fishery Sciences

Box 355020

University of Washington

Seattle, Washington 98195 USA

Telephone: 206.543.5997

Email: scheuerl@uw.edu 


\section{Summary}

2 1. Assessing the degree to which at-risk species are regulated by density dependent versus

3 density independent factors is often complicated by incomplete or biased information. If not

4 addressed in an appropriate manner, errors in the data can affect estimates of population

5 demographics, which may obfuscate the anticipated response of the population to a specific

6 action.

7 2. We developed a Bayesian integrated population model that accounts explicitly for interannual

8 variability in the number of reproducing adults and their age structure, harvest, and

9 environmental conditions. We apply the model to 41 years of data for a population of threatened

10 steelhead trout Oncorhynchus mykiss using freshwater flows, ocean indices, and releases of

11 hatchery-born conspecifics as covariates.

12 3. We found compelling evidence that the population is under strong density dependence, despite

13 being well below its historical population size. In the freshwater portion of the lifecycle, we

14 found a negative relationship between productivity (offspring per parent) and peak winter flows,

15 and a positive relationship with summer flows. We also found a negative relationship between

16 productivity and releases of hatchery conspecifics. In the marine portion of the lifecycle, we

17 found a positive correlation between productivity and the North Pacific Gyre Oscillation.

18 Furthermore, harvest rates on wild fish have been sufficiently low to ensure very little risk of

19 overfishing.

20 4. Synthesis and applications. The evidence for density dependent population regulation,

21 combined with the substantial loss of juvenile rearing habitat in this river basin, suggests that

22 habitat restoration could benefit this population of at-risk steelhead. Our results also imply that

23 hatchery programs for steelhead need to be considered carefully with respect to habitat 
bioRxiv preprint doi: https://doi.org/10.1101/734996; this version posted August 15,2019 . The copyright holder for this preprint (which was not certified by peer review) is the author/funder, who has granted bioRxiv a license to display the preprint in perpetuity. It is made available under aCC-BY-NC-ND 4.0 International license.

24 availability and recovery goals for wild steelhead. If releases of hatchery steelhead have indeed

25 limited the production potential of wild steelhead, there are likely significant tradeoffs between

26 providing harvest opportunities via hatchery steelhead production, and achieving wild steelhead

27 recovery goals. 


\section{Introduction}

Managing at-risk species requires an understanding of the degree to which population dynamics are self-regulated versus driven by external factors. However, the data used to identify potentially important density-dependent and population-environment relationships are rarely, if ever, fully comprehensive or error free. Rather, imperfect detection, misidentification, and nonexhaustive sampling all lead to a somewhat distorted view of the true state of nature. For example, when not addressed in an appropriate manner, errors in population censuses may cause underestimates of recruitment (Sanz-Aguilar et al. 2016) or overestimates of the strength of density dependence (Knape \& de Valpine 2012). Similarly, imprecision in the estimated age composition of the population also biases the estimated strength of density dependence (Zabel \& Levin 2002). In a conservation context, these erroneous conclusions may directly influence the anticipated response of a population to a specific action. Therefore, proper consideration of all sources of uncertainty in the data is necessary to design robust management strategies aimed at protecting at-risk species.

The productivity and carrying capacity of a population may also vary over time and space (Thorson et al. 2015), and explicit consideration of external drivers can improve estimates of population dynamics under density dependent conditions (Lebreton \& Gimenez 2013). For atrisk species, these exogenous factors can be used to better understand drivers of historical population demographics and help identify possible recovery options. Incorporating covariates into population models can also improve forecasts of future dynamics, especially over shorter time horizons most relevant to natural resource management (Ward et al. 2014). Furthermore, accelerated global change will likely create synergistic effects that complicate efforts to make reliable long-term predictions (Schindler \& Hilborn 2015). Thus, any reasonable assumptions 
51 about future responses of populations should begin with an attempt to fully account for the uncertainty in population-environment relationships based on all of the available information. Many populations of Pacific salmon (Oncorhynchus spp.) throughout the northwestern United States have declined markedly since the early 1900s due to a variety of causes such as habitat alteration, hydropower development, and overharvest (Ruckelshaus et al. 2002). For conservation purposes, Pacific salmon species are grouped into evolutionarily significant units (ESU, Waples 1991); 28 of the 49 extant ESUs of Pacific salmon are currently listed as "threatened" or "endangered" under the U.S. Endangered Species Act. As a result, a number of life-cycle models have been developed to evaluate the possible future benefits of conservation actions such as habitat restoration (e.g., Scheuerell et al. 2006) and the potentially negative consequences of climate change (e.g., Zabel et al. 2006). However, these models were assembled by first obtaining parameter values from the literature, or estimating them from disparate data sources, and then putting all of the pieces together post hoc. Consequently, they do not reflect a comprehensive assessment of the total uncertainty in population demographics.

More recently however, researchers have turned toward integrated population models (IPMs) as a means to convey the combined uncertainty in all of the data sources, which is particularly important in a conservation context (Buhle et al. 2018; Zipkin \& Saunders 2018). IPMs are similar to state-space models in that they have specific sub-models for 1) describing the stochastic and unobservable population dynamics; and 2) addressing the noisy, incomplete data (Schaub \& Abadi 2011; Maunder \& Punt 2013; Yen et al. 2019). Although IPMs have been widely developed and applied to mammals (e.g., Eacker et al. 2017; Regehr et al. 2018) and birds (e.g., Crawford et al. 2018; Saunders, Cuthbert \& Zipkin 2018), there are very few examples for Pacific salmon (cf., Buhle et al. 2018). 
Here we combine incomplete data on adult abundance, age composition, and harvest into

a Bayesian IPM to answer important questions relevant to management of a threatened population of anadromous steelhead trout Oncorhynchus mykiss Walbaum 1792 from the Skagit River basin, which drains $\sim 6900 \mathrm{~km}^{2}$ in southwestern Canada and northwestern United States. Specifically, we used 39 years of age structured abundance data (1978-2018) to quantify the degree of density dependence and the effects of a specific suite of environmental drivers on intrinsic productivity within the Skagit River steelhead population. We found that although recent population censuses are well below historical estimates, the population still operates under relatively strong density dependence. We also found that streamflow during winter and releases of hatchery-reared juvenile steelhead were negatively related to wild steelhead survival, but that survival was positively related to streamflow during summers as juveniles and sea-surface temperatures experienced as adults in the North Pacific. In light of remaining uncertainty in the factors governing the population dynamics of Skagit River steelhead, this modelling framework is an effective tool for setting near term recovery goals and evaluating population level response recovery actions.

\section{Materials and methods}

\section{STUDY SPECIES AND DATA}

The Skagit River system is predominantly a glacially fed system that consists of a combination of rain, snow-transitional, and snow-dominated tributaries providing approximately $48 \mathrm{~km}^{2}$ of potential habitat suitable for spawning and rearing by wild winter run steelhead (Hard et al. 2015). Adult steelhead trout in the Skagit River generally enter freshwater in November through April and typically spawn in March through June. The majority of juveniles rear in freshwater for 2 years prior to migrating to sea as smolts where they spend 2 to 6 years feeding 
97

98

99

100

101

102

103

104

105

106

107

108

109

110

111

112

113

114

115

116

117

118

119

and growing before returning to freshwater as sexually mature adults to initiate spawning (i.e., they reach sexual maturity at age three through eight; $\sim 82 \%$ mature at age four or five). Scale samples taken from wild steelhead indicate that, on average, $9 \%$ of returning adults are repeat spawners. These fish then spend a year at sea before returning again to freshwater to spawn again.

Due to a combination of logistical constraints, only a fraction of the known spawning area was surveyed for wild spawners. Specifically, standardized index reach surveys were conducted annually in only 2 of 5 major sub-basins and 13 of 63 tributaries known to support wild steelhead production. A basin-wide estimate of wild spawners was generated annually by expanding each survey to account for estimated available habitat not surveyed. Fisheries biologists in the Skagit basin generally consider the escapement estimates to be conservative: it is more likely that escapement is underestimated than overestimated because unobserved spawning sites would serve to increase abundance. Our analyses begin with surveys in 1978 and continue through 2018.

In the model described below, we evaluate several environmental indicators of survival. Specifically, flow conditions experienced by juveniles during freshwater rearing can have strong effects on their survival to adulthood via the following mechanisms: (1) spatial contraction of habitat as a result of low summer flows and high water temperatures that coincide with the period of highest metabolic demand (e.g., Crozier et al. 2010), and (2) habitat displacement or direct mortality resulting from peak winter flows (e.g., Irvine 1986). Therefore, we utilized longterm flow records from a gage (\#12178100) located in Newhalem Creek, a snowmelt dominated stream located in the Upper Skagit River (48.66 N, 121.246 W), and maintained by the United States Geological Survey (see Appendix S1 in Supporting Information for details). Specifically, 
120 we obtained the observed maximum of daily peak flows occurring from October through March

121 of the first freshwater rearing year, and the minimum of low summer flows occurring from June

122 through September of the first summer of freshwater rearing.

123 Because conditions experienced by salmon and steelhead during their first year at sea are

124 thought to be critical to overall survival and growth of a given year class (Beamish \& Mahnken

125 2001), we chose the average North Pacific Gyre Oscillation index (NPGO) from January through

126 December as an index of conditions experienced by juvenile steelhead during their first year in

127 the ocean. Variability in the NPGO reflects annual changes in coastal upwelling and ocean

128 circulation patterns that correlate strongly with primary and secondary production in coastal

129 ecosystems (Di Lorenzo et al. 2008). Furthermore, the NPGO has been recently identified as an

130 important indicator of early marine survival in other Pacific salmon species (Kilduff et al. 2015).

131 Because most juvenile steelhead from the Skagit River migrate to sea during the spring of their

132 second year, we lagged the NPGO indicator by two years beyond the birth year to reflect

133 conditions experienced during the first year at sea.

134 From a management standpoint, we were interested in the possible effect of hatchery-

135 reared juvenile steelhead on the productivity of wild steelhead. The Washington Department of

136 Fish and Wildlife operates a "segregated" steelhead hatchery program (sensu Mobrand et al.

137 2005) that uses broodstock from a non-local source intentionally bred for early spawning, with

138 the goal of minimizing temporal reproductive overlap with wild fish and hence minimizing gene

139 flow into the wild population. Over the time series, hatchery fish were typically reared to age-1

140 and released in the spring (April or May) from multiple locations in the Skagit Basin. We

141 hypothesized that hatchery fish would have the greatest potential for conspecific ecological

142 interactions during the time juvenile steelhead are migrating to sea because observations at a 
143 juvenile fish trap (river $\mathrm{km} 27$ ) indicate they overlap in time and space. Therefore, we assumed

144 that a cohort born in year $t$ would interact with hatchery fish released in year $t+2$. We used the

145 total number of juveniles released from the hatchery within a given year as our covariate.

146 INTEGRATED POPULATION MODEL

147 The IPM we describe here expands upon models developed by others (e.g., Su \&

148 Peterman 2012; Fleischman et al. 2013; Winship, O'Farrell \& Mohr 2014) in that we include the

149 effects of extrinsic drivers on population dynamics. As with other IPMs, our model comprises

150 two major components: a process model describing the production of age-specific offspring, and

151 observation models to account for errors in the estimates of spawning escapement and age

152 composition. Following other, more traditional analyses of Pacific salmon population dynamics,

153 our modeling framework also assumes no consistent bias in estimates of adult spawners or age

154 composition of returning adults.

We begin with our process model where the number of offspring born in year $t$ that

156 survive to adulthood $\left(R_{t}\right)$ equals the product of a nonlinear function of the number of spawning

157 adults $\left(S_{t}\right)$ and a time-varying stochastic error $\varepsilon_{t}$ :

158

$$
R_{t}=f\left(S_{t} \mid \boldsymbol{\theta}\right) \mathrm{e}^{\varepsilon_{t}}
$$

159 Here we consider two different forms for $f$ : the Ricker model (Ricker 1954) and the Beverton-

160 Holt model (Beverton \& Holt 1957); see Fig. 1 for model forms and descriptions of their 161 parameters and associated reference points.

The process errors $\left(\varepsilon_{t}\right)$ are often assumed to be independent draws from a Gaussian

163 distribution with a mean of zero and an unknown variance. However, the stochastic

164 environmental drivers that the $\varepsilon_{t}$ are meant to represent typically show relatively strong 
autocorrelation over time. Thus, we compared two different distributional forms for $\varepsilon_{t}$ with nonzero, autocorrelated means. In the first, we assumed that

$$
\begin{aligned}
\varepsilon_{t} & \sim \operatorname{Normal}\left(\phi \varepsilon_{t-1}, \sigma_{\varepsilon}\right), \\
\varepsilon_{0} & \sim \operatorname{Normal}\left(0, \frac{\sigma_{\varepsilon}}{1-\phi^{2}}\right) .
\end{aligned}
$$

Second, we considered models where the non-zero means were also a function of the various environmental drivers important to salmon survival as discussed above. In those models,

$$
\varepsilon_{t} \sim \operatorname{Normal}\left(\mu_{t}+\phi \varepsilon_{t-1}, \sigma_{\varepsilon}\right)
$$

Here, $\gamma_{i}$ is the effect of covariate $X_{i}$ measured at time $t$ and shifted by an appropriate lag $h_{i}$ based on the life stage that the covariate would affect most strongly. We standardized all covariates to have zero-mean and unit-variance to facilitate direct comparison of effect sizes.

The estimated numbers of fish of age $a$ returning in year $t\left(N_{a, t}\right)$ is then product of the total number of brood-year recruits in year $t-a$ from Equation (1) and the proportion of mature fish from that brood year that returned to spawn at age $a\left(\pi_{a, t-a}\right)$, such that

$$
N_{a, t}=R_{t-a} \pi_{a, t-a}
$$

Adult steelhead from the Skagit River return as 3-8 year-olds, and therefore the vector of agespecific return rates for brood year $t$ is $\pi_{t}=\left[\pi_{3}, \pi_{4}, \pi_{5}, \pi_{6}, \pi_{7}, \pi_{8}\right]$, which we modeled as a hierarchical random effect whereby $\pi_{t} \sim \operatorname{Dirichlet}(\eta \tau)$. The mean vector $\eta$ is also distributed as a Dirichlet; the precision parameter $\tau$ affects each of the elements in $\eta$ such that large values of $\tau$ result in $\pi_{t}$ very close to $\eta$ and small values of $\tau$ lead to much more diffuse $\pi_{t}$.

The spawner-recruit models above describe a process based on the true number of spawners, but our estimates of the numbers of spawning adults necessarily contain some sampling errors due to incomplete censuses, pre-spawn mortality, etc. Therefore, we assumed 
that our estimates of escapement, the number of adult fish that "escape the fishery" and ultimately spawn $\left(E_{t}\right)$, are log-normally distributed about the true number of spawners $\left(S_{t}\right)$ :

$$
\ln \left(E_{t}\right) \sim \operatorname{Normal}\left(\ln \left(S_{t}\right), \sigma_{s}\right)
$$

Catches of wild steelhead are closely recorded by state and tribal biologists, and so we assume the harvest is recorded without error. We then calculate $S_{t}$ as the difference between the estimated total run size $\left(N_{t}\right)$ and harvest $\left(H_{t}\right)$, where

$$
S_{t}=N_{t}-H_{t}
$$

and $N_{t}$ is the sum of $N_{a, t}$ from Equation (3) over all age classes.

We obtained observations of the number of fish in each age class $a$ in year $t\left(O_{a, t}\right)$ from scale analyses of 10 - 408 adults per year; no scale samples were taken in 1978-1982, 1984, and 2000. These data were assumed to arise from a multinomial process with order $Y_{t}$ and proportion vector $\mathbf{d}_{t}$, such that

$$
\mathbf{O}_{t} \sim \operatorname{Multinomial}\left(Y_{t}, \mathbf{d}_{t}\right) \text {. }
$$

The order of the multinomial is simply the sum of the observed numbers of fish across all ages returning in year $t$ :

$$
Y_{t}=\sum_{a=3}^{8} O_{t, a}
$$

The proportion vector $\mathbf{d}_{t}$ for the multinomial is based on the age-specific, model-derived estimates of adult returns in year $t\left(N_{a, t}\right)$ such that

$$
d_{a, t}=\frac{N_{a, t}}{\sum_{a=3}^{8} N_{a, t}} .
$$

We used Bayesian inference to estimate all model parameters and the unobserved true numbers of spawners and offspring over time. We used the freely available $\mathrm{R}$ software (v3.6, R Development Core Team 2019) combined with the JAGS software (v4.2.0, Plummer 2003) to perform Gibbs sampling with 4 parallel chains of $5 \times 10^{5}$ iterations. Following a burn-in period of 
$2112.5 \times 10^{5}$ iterations, we thinned each chain by keeping every $400^{\text {th }}$ sample to eliminate any

212 possible autocorrelation, which resulted in 5000 samples from the posterior distributions. We

213 assessed convergence and diagnostic statistics via the 'CODA' package in R (Plummer et al.

214 2006). Specifically, we used visual inspection of trace plots and density plots, and verified that

215 Gelman and Rubin's (2017) potential scale reduction factor was less than 1.1, to ensure adequate

216 chain mixing and parameter convergence. Data support for each model was evaluated using

217 leave-one-out cross-validation (LOO) based upon Pareto-smoothed importance sampling

218 (Vehtari, Gelman \& Gabry 2017) as implemented in the 'loo' package (Vehtari et al. 2019). All

219 of the code and data files necessary to replicate our analyses are available in the online

220 supporting material and at https://github.com/mdscheuerell/skagit_sthd.

\section{Results}

We found the most data support for the Beverton-Holt form of process model, so all of the following results are based upon it (see Appendix S2 for full model selection results). Our estimates of the total population size reflect the uncertainty in the estimated numbers of adults over time, but the median values agreed quite well with the observed data (Fig. 2). As expected, the $95 \%$ credible intervals were widest in 1996 and 1997 when there were no direct estimates of spawning adults.

The population dynamics of steelhead in the Skagit River are currently under densitydependent regulation, despite their numbers being well below historical censuses, and there is considerable uncertainty in the relationship between spawning adults and their surviving offspring (Fig. 3). The median of $\alpha$ (i.e., the slope of the relationship at the origin) was 6.8 offspring per spawner, but a lack of data at low spawner abundance led to considerable uncertainty in the estimate (Fig. 3b). The lower 95\% credible interval was about 1.5 offspring per 
234

235

236

237

238

239

240

241

242

243

244

245

246

247

248

249

250

251

252

253

254

255

256

spawner, which is still above replacement, while the upper $95 \%$ credible interval was 44

offspring per parent. On the other hand, our estimates of carrying capacity $(K)$ were much more precise, with a median of about 7400 adults and 95\% credible interval of approximately 6100 to 10900 adults (Fig. 3c).

There were varying effects of the three environmental covariates on population productivity (Fig. 4). Peak winter flows were negatively related to survival, suggesting high discharge events may transport juveniles downstream to lower quality habitats, or lead to direct mortality from channel avulsion or movement of sediment, wood, and other debris. The median of the posterior distribution was -0.11 (Fig. 4e), which means that a 1 SD increase in flow above the mean (i.e., from $\sim 41 \mathrm{~m}^{3} \mathrm{~s}^{-1}$ to $\sim 68 \mathrm{~m}^{3} \mathrm{~s}^{-1}$ ) would translate into a $11 \%$ decrease in offspring per parent. Conversely, the effect of low summer flows was positive (Fig. 4f), possibly indicative of greater rearing habitat (the median estimate was 0.08 with a $95 \%$ credible interval of -0.09 to 0.25). The NPGO had a similar effect to summer flow (Fig. 4g), suggesting warmer waters in the North Pacific are better for steelhead survival (median equals 0.09 with a $95 \%$ credible interval of -0.08 to 0.27 .

We also found that the number of hatchery juveniles released into the river during the time that wild juveniles were migrating to sea was negatively related to productivity (Fig. $4 \mathrm{~h}$ ). The median effect size was -0.20 , which means that a 1 SD increase in the number of hatchery juveniles released (i.e., from 328000 to 452000 fish) would, on average, result in a 18\% decrease in survival to adulthood. Notably, hatchery production experienced three distinct phases over time (Fig. 4d): a low period between brood year 1978 and 1990 (range $=125000$ to 340 000 smolts), an increasing and high period between 1991 and 2005 (range = 314000 to 584 000), and a decreasing period beginning in 2006 (range $=0$ to 240000 smolts). 
The remaining, unexplained environmental variance was indeed highly autocorrelated over time (Fig. 5). The process residuals were generally positive during the late 1970s and early 1980s when the population was growing (Fig. 2), they were near zero during the stable period of the 1990 s, and then largely negative as the population primarily declined through the 2000 s. Based on our estimates of biological reference points, Skagit River steelhead appear to be managed along a rather conservative harvest management perspective. The optimal yield profiles suggest it would take approximately 2000 to 3000 spawning adults to produce the maximum sustainable yield (Fig. 6a), but very few years have ever fallen below that throughout the time period presented here (i.e., the average number of spawning adults has been two to three times greater). In other words, the realized harvest rates have been kept low enough to insure very little risk of overfishing (Fig. 6b).

\section{Discussion}

In territorial species such as steelhead trout, competition for limited resources commonly results in density dependent growth and survival amongst juveniles (Imre, Grant \& Keeley 2004). Our analysis suggests that such effects have scaled up to the entire population level to govern patterns of steelhead productivity in the Skagit River basin. Importantly, we found strong evidence for density dependent interactions despite the fact that contemporary population censuses are well below historical estimates (Gayeski, McMillan \& Trotter 2011). Similar results have been observed in populations of coho salmon Oncorhynchus kisutch Walbaum 1792 in Oregon (Buhle et al. 2009) and in populations of Chinook salmon Oncorhynchus tshawytscha Walbaum 1792 in Idaho (Thorson et al. 2013). Although we cannot be certain of the exact lifestage at which density dependent processes occurred, the freshwater juvenile stage seems likely given the extended duration of freshwater rearing typical for this species. When steelhead 
populations reach low numbers, the spatial contraction of spawners may exacerbate the effects of density dependence because their newly emerged offspring do not have the mobility to access other vacant habitats (Atlas et al. 2015). The evidence for density dependence presented here, combined with the substantial loss of juvenile rearing habitat in the Skagit River basin (Beechie, Beamer \& Wasserman 1994), suggests that habitat restoration efforts, such as reconnecting floodplain habitats and improving riparian functioning (Beechie, Pess \& Roni 2008), may benefit this population of steelhead.

Fluctuating environments can also affect population dynamics through density independent mechanisms, and anadromous salmon must contend with many different and unpredictable habitats over their lifespan. Our results indicate that in the freshwater environment, large flow events during winter negatively affect steelhead productivity. Unfortunately, this may portend an uncertain future for these fish. In a recent study, Lee et al. (2015) estimated that future climate change in the Skagit River basin would create increased winter flows. These changes in hydrology will likely result in much greater exposure of steelhead to extreme high flow events due to their duration, intensity, and timing (Wade et al. 2013). Other evidence already exists that freshwater discharge from Puget Sound rivers has become much more variable, with notable negative effects on Chinook salmon Oncorhynchus tshawytscha Walbaum 1792 (Ward et al. 2015). Furthermore, although we found a somewhat weaker relationship between low summer flow and productivity, extreme low-flow events are projected to occur at a higher frequency in the future (Lee et al. 2015).

We found evidence of positive effects of NPGO on survival, which comports with previous studies that have made rather compelling cases for a strong positive relationship between the NPGO and salmon survival (Kilduff et al. 2015). The NPGO is a synoptic measure 
303 of ocean conditions over a large region of the North Pacific Ocean (Kilduff et al. 2015), so we

304 cannot say where and when, exactly, the effects of the ocean environment most manifest

305 themselves. Recent evidence also indicates that steelhead smolts suffer high mortality during

306 their relatively brief migration through Puget Sound (Moore et al. 2015), possibly due to

307 predation by marine mammals (Berejikian, Moore \& Jeffries 2016). Notably, too, the residual

308 process errors not captured by our covariates ( $w_{t}$ in Equation 1) were correlated with the

309 estimated marine survival of Skagit River hatchery steelhead (median Pearson's correlation

310 coefficient $=0.29 ; 95 \%$ credible interval $=[0.03,0.50])$, suggesting marine processes not

311 captured by our covariates likely influenced productivity.

Among the various mitigation measures to address salmon declines, artificial propagation

313 of salmon has been used widely for more than a century. Nevertheless, research in other river

314 systems points to negative ecological effects of hatchery fish on wild Pacific salmon, including

315 populations coho salmon (Buhle et al. 2009), and Chinook salmon (Levin, Zabel \& Williams

316 2001). Our results provide further evidence that large releases of hatchery-reared juvenile

317 steelhead have had a negative effect on productivity of wild steelhead, although we note some

318 researchers have used an approach similar to ours and found no hatchery effect on productivity

319 (Courter et al. 2019; Nelson et al. 2019). Our study was unable determine the mechanism

320 responsible for the correlation between hatchery releases and wild steelhead productivity. In fact,

321 very few empirical studies have been conducted at the appropriate spatial and temporal scales

322 necessary to directly quantify the hypothesized mechanisms by which negative ecological

323 interactions between hatchery and wild fish may occur (Weber \& Fausch 2003). That said,

324 however, competition for limiting freshwater food and habitat resources (Berejikian et al. 2000)

325 is a plausible mechanism, either during the relatively brief period of overlap during downstream 

347 estimated effect sizes. productivity.

migration (ca. 2 - 4 weeks), or a more prolonged effect of any hatchery fish that do not migrate to sea, but instead "residualize" within freshwater. Additionally, predators are known to respond numerically to their prey, and it is possible that large numbers of hatchery fish attracted additional predators (Kostow 2009). Although breeding by hatchery individuals that stray onto natural spawning grounds may reduce the fitness of a wild population via gene flow from the hatchery stock into the wild population (Araki, Cooper \& Blouin 2009), our study only considered within-cohort effects. Thus, it seems unlikely that a trans-generational genetic effect was the mechanism for the observed negative association between hatchery releases and wild

Throughout the Puget Sound region, steelhead have been exposed to varying degrees of influence by hatchery fish over the past 100 years, but they share the marine rearing environment, and thus have experienced relatively similar ocean conditions during the same time period. The marked decreases in abundance observed in many of these populations from the late 1980 s to the late 2000 's, including the Skagit, mirrors observations of a general declining trend in marine survival of hatchery conspecifics across the same time period, suggesting some larger, unmeasured forces have been at work (Kendall, Marstrom \& Klungle 2017). Furthermore, in response to the declining abundance of wild Skagit River steelhead coupled with declining marine survival of hatchery steelhead, fisheries managers increased hatchery production to replace lost fishing opportunities. Thus, it is plausible that declining wild productivity was simply coincident with higher hatchery production, rather than a consequence of it. It is also possible that multicollinearity among measured and unmeasured covariates increased the 

trade-off between catch and the risk of over-fishing such that minimizing the risk of overfishing takes precedence (Hilborn et al. 2001). Our Bayesian state-space model provides a formal means

362 for estimating the probability of fishing in a sustainable manner. We found compelling evidence 363 that harvest rates for wild steelhead in the Skagit River basin over the time period considered

364 here have been well below those that would drive the population toward extinction. This result, combined with the strong indication of density dependence, lends further support to the notion

367 because we may have overestimated the biological reference points by not fully accounting for repeat spawners. 
natural and human-induced variability in the environment. Our study adds to the growing body

372 of evidence that habitat, hatchery practices, and environmental variability are intricately linked in

373 affecting productivity of wild Pacific salmon stocks. Future research should focus on quantifying

374 habitat limitation on productivity at specific life stages to better focus restoration actions needed

375 to recover wild steelhead. Our modeling framework also allowed us to assess the degree to which

376 hatchery and harvest management actions are likely to affect the long-term viability of the

377 population. Our results suggest that hatchery program goals for steelhead need to be considered

378 carefully with respect to recovery goals and the quantity and quality of steelhead habitat. If

379 releases of non-local origin hatchery steelhead have indeed limited the production potential of

380 wild steelhead, there are likely significant tradeoffs between providing harvest opportunities via

381 hatchery steelhead production and achieving wild steelhead recovery goals.

382

\section{Acknowledgements}

We thank Eric Buhle and Jim Thorson for helpful discussions about model development. We also thank Rebecca Bernard, Pete Kairis, Brett Barkdull, Andrew Fowler, and numerous WDFW, Sauk-Suiattle, Swinomish, and Upper Skagit tribal biologists who compiled the escapement and age data. Annette Hoffman, Dan Rawding, Kris Ryding, and James Scott provided constructive criticism. This research was funded in part by a NOAA Fisheries And The Environment (FATE) grant (\#15-01), and an Environmental Protection Agency Tribal Capacity grant (\#PA-00J32001).

\section{Authors' Contributions}

MS, CR and JA conceived the ideas and designed methodology; MS and CR analysed the data;

MS and CR led the writing of the manuscript. All authors contributed critically to the drafts and gave final approval for publication. 


\section{Data Accessibility}

395 All of the fish data have been archived at Figshare and are available via the following links:

396 abundance (https://dx.doi.org/10.6084/m9.figshare.3458183.v1);

397 age composition (https://dx.doi.org/10.6084/m9.figshare.3458204.v1);

398 harvest (https://dx.doi.org/10.6084/m9.figshare.3458189.v1); and

399 hatchery releases (https://dx.doi.org/10.6084/m9.figshare.3457163.v1).

400 The river flow data are available from the United States Geological Survey National Water

401 Information System (http://waterdata.usgs.gov/nwis). The North Pacific Gyre Oscillation data

402 are available from Emanuele Di Lorenzo at Georgia Technical University

403 (http://www.o3d.org/npgo/). 
404

405

406

407

408

409

410

411

412

413

414

415

416

417

418

419

420

421

422

423

424

425

426

\section{REFERENCES}

Ahrestani, F.S., Saracco, J.F., Sauer, J.R., Pardieck, K.L. \& Royle, J.A. (2017) An integrated population model for bird monitoring in North America. Ecological Applications, 27, 916-924.

Araki, H., Cooper, B. \& Blouin, M.S. (2009) Carry-over effect of captive breeding reduces reproductive fitness of wild-born descendants in the wild. Biology Letters, 5, 621-624.

Atlas, W.I., Buehrens, T.W., McCubbing, D.J.F., Bison, R. \& Moore, J.W. (2015) Implications of spatial contraction for density dependence and conservation in a depressed population of anadromous fish. Canadian Journal of Fisheries and Aquatic Sciences, 72, 1682-1693.

Beamish, R.J. \& Mahnken, C. (2001) A critical size and period hypothesis to explain natural regulation of salmon abundance and the linkage to climate and climate change. Progress in Oceanography, 49, 423-437.

Beechie, T., Pess, G. \& Roni, P. (2008) Setting river restoration priorities: a review of approaches and a general protocol for identifying and prioritizing actions. North American Journal of Fisheries Management, 28, 891-905.

Beechie, T.J., Beamer, E.M. \& Wasserman, L. (1994) Estimating coho salmon rearing habitat and smolt production losses in a large river basin, and implications for habitat restoration. North American Journal of Fisheries Management, 14, 797-811.

Berejikian, B.A., Moore, M.E. \& Jeffries, S.J. (2016) Predator-prey interactions between harbor seals and migrating steelhead trout smolts revealed by acoustic telemetry. Marine Ecology Progress Series, 543, 21-35.

Berejikian, B.A., Tezak, E.P., Flagg, T.A., LaRae, A.L., Kummerow, E. \& Mahnken, C.V.W. (2000) Social dominance, growth, and habitat use of age-0 steelhead (Oncorhynchus 
mykiss) grown in enriched and conventional hatchery rearing environments. Canadian Journal of Fisheries and Aquatic Sciences, 57, 628-636.

Beverton, R.J.H. \& Holt, S.J. (1957) On the Dynamics of Exploited Fish Populations. Fishery Investigations Series II Volume XIX, Ministry of Agriculture, Fisheries and Food, London.

Buhle, E.R., Holsman, K.K., Scheuerell, M.D. \& Albaugh, A. (2009) Using an unplanned experiment to evaluate the effects of hatcheries and environmental variation on threatened populations of wild salmon. Biological Conservation, 142, 2449-2455.

Buhle, E.R., Scheuerell, M.D., Cooney, T.D., Ford, M.J., Zabel, R.W. \& Thorson, J.T. (2018) Using Integrated Population Models to Evaluate Fishery and Environmental Impacts on Pacific Salmon Viability. U.S. Department of Commerce, NOAA Technical Memorandum NMFS-NWFSC-140.

Courter, II, Wyatt, G.J., Perry, R.W., Plumb, J.M., Carpenter, F.M., Ackerman, N.K., Lessard, R.B. \& Galbreath, P.F. (2019) A Natural-Origin Steelhead Population's Response to Exclusion of Hatchery Fish. Transactions of the American Fisheries Society, 148, 339351.

Crawford, B.A., Moore, C.T., Norton, T.M. \& Maerz, J.C. (2018) Integrated analysis for population estimation, management impact evaluation, and decision-making for a declining species. Biological Conservation, 222, 33-43.

Crozier, L.G., Zabel, R.W., Hockersmith, E.E. \& Achord, S. (2010) Interacting effects of density and temperature on body size in multiple populations of Chinook salmon. Journal of Animal Ecology, 79, 342-349. 
Di Lorenzo, E., Schneider, N., Cobb, K.M., Franks, P.J.S., Chhak, K., Miller, A.J., McWilliams, J.C., Bograd, S.J., Arango, H., Curchitser, E., Powell, T.M. \& Riviere, P. (2008) North Pacific Gyre Oscillation links ocean climate and ecosystem change. Geophysical Research Letters, 35, 6.

Eacker, D.R., Lukacs, P.M., Proffitt, K.M. \& Hebblewhite, M. (2017) Assessing the importance of demographic parameters for population dynamics using Bayesian integrated population modeling. Ecological Applications, 27, 1280-1293.

Fleischman, S.J., Catalano, M.J., Clark, R.A. \& Bernard, D.R. (2013) An age-structured statespace stock-recruit model for Pacific salmon (Oncorhynchus spp.). Canadian Journal of Fisheries and Aquatic Sciences, 70, 401-414.

Gayeski, N., McMillan, B. \& Trotter, P. (2011) Historical abundance of Puget Sound steelhead, Oncorhynchus mykiss, estimated from catch record data. Canadian Journal of Fisheries and Aquatic Sciences, 68, 498-510.

Hard, J.J., Myers, J.M., Connor, E.J., Hayman, R.A., Kope, R.G., Lucchetti, G., Marshall, A.R., Pess, G.R. \& Thompson, B.E. (2015) Viability Criteria for Steelhead within the Puget Sound Distinct Population Segment. U.S. Dept. Commerce, NOAA Tech. Memo. NMFSNWFSC-129., Springfield, VA.

Hilborn, R., Maguire, J.J., Parma, A.M. \& Rosenberg, A.A. (2001) The Precautionary Approach and risk management: can they increase the probability of successes in fishery management? Canadian Journal of Fisheries and Aquatic Sciences, 58, 99-107.

Imre, I., Grant, J.W.A. \& Keeley, E.R. (2004) The effect of food abundance on territory size and population density of juvenile steelhead trout (Oncorhynchus mykiss). Oecologia, 138, $371-378$. 
Irvine, J.R. (1986) Effects of varying discharge on the downstream movement of salmon fry, Oncorhynchus tshawytscha Walbaum. Journal of Fish Biology, 28, 17-28.

Kendall, N.W., Marstrom, G.W. \& Klungle, M.M. (2017) Declining patterns of Pacific Northwest steelhead trout (Oncorhynchus mykiss) adult abundance and smolt survival in the ocean. Canadian Journal of Fisheries and Aquatic Sciences, 74, 1275-1290.

Kendall, N.W., McMillan, J.R., Sloat, M.R., Buehrens, T.W., Quinn, T.P., Pess, G.R., Kuzishchin, K.V., McClure, M.M. \& Zabel, R.W. (2015) Anadromy and residency in steelhead and rainbow trout (Oncorhynchus mykiss): a review of the processes and patterns. Canadian Journal of Fisheries and Aquatic Sciences, 72, 319-342.

Kilduff, D.P., Di Lorenzo, E., Botsford, L.W. \& Teo, S.L.H. (2015) Changing central Pacific El Niños reduce stability of North American salmon survival rates. Proceedings of the National Academy of Sciences.

Knape, J. \& de Valpine, P. (2012) Are patterns of density dependence in the Global Population Dynamics Database driven by uncertainty about population abundance? Ecology Letters, $15,17-23$.

Kostow, K. (2009) Factors that contribute to the ecological risks of salmon and steelhead hatchery programs and some mitigating strategies. Reviews in Fish Biology and Fisheries, 19, 9-31.

Lebreton, J.D. \& Gimenez, O. (2013) Detecting and estimating density dependence in wildlife populations. Journal of Wildlife Management, 77, 12-23.

Lee, A.M., Bjorkvoll, E.M., Hansen, B.B., Albon, S.D., Stien, A., Saether, B.E., Engen, S., Veiberg, V., Loe, L.E. \& Grotan, V. (2015) An integrated population model for a longlived ungulate: more efficient data use with Bayesian methods. Oikos, 124, 806-816. 
495

496

497

498

499

500

501

502

503

504

505

506

507

508

509

510

511

512

513

514

515

516

Levin, P.S., Zabel, R.W. \& Williams, J.G. (2001) The road to extinction is paved with good intentions: negative association of fish hatcheries with threatened salmon. Proceedings of the Royal Society of London B Biological Sciences, 268, 1153-1158.

Maunder, M.N. \& Punt, A.E. (2013) A review of integrated analysis in fisheries stock assessment. Fisheries Research, 142, 61-74.

Mobrand, L.E., Barr, J., Blankenship, L., Campton, D.E., Evelyn, T.T.P., Flagg, T.A., Mahnken, C.V.W., Seeb, L.W., Seidel, P.R., Smoker, W.W. \& Hatchery Sci Rev, G. (2005) Hatchery reform in Washington state: Principles and emerging issues. Fisheries, 30, 1123.

Moore, M.E., Berejikian, B.A., Goetz, F.A., Berger, A.G., Hodgson, S.S., Connor, E.J. \& Quinn, T.P. (2015) Multi-population analysis of Puget Sound steelhead survival and migration behavior. Marine Ecology Progress Series, 537, 217-232.

Nelson, B.W., Walters, C.J., Trites, A.W. \& McAllister, M.K. (2019) Wild Chinook salmon productivity is negatively related to seal density and not related to hatchery releases in the Pacific Northwest. Canadian Journal of Fisheries and Aquatic Sciences, 76, 447-462.

Plummer, M. (2003) JAGS: A program for analysis of Bayesian graphical models using Gibbs sampling. Proceedings of the 3rd International Workshop on Distributed Statistical Computing. Vienna, Austria.

Plummer, M., Best, N., Cowles, K. \& Vines, K. (2006) CODA: Convergence Diagnosis and Output Analysis for MCMC. R News, 6, 7-11.

R Development Core Team (2019) R: A Language and Environment for Statistical Computing. R Foundation for Statistical Computing, Vienna, Austria. 
Regehr, E.V., Hostetter, N.J., Wilson, R.R., Rode, K.D., St Martin, M. \& Converse, S.J. (2018) Integrated population modeling provides the first empirical estimates of vital rates and abundance for polar bears in the Chukchi Sea. Scientific Reports, $\mathbf{8}$.

Ricker, W.E. (1954) Stock and recruitment. Journal of the Fisheries Research Board of Canada, $11,559-623$.

Ruckelshaus, M.H., Levin, P., Johnson, J.B. \& Kareiva, P.M. (2002) The Pacific salmon wars: what science brings to the challenge of recovering species. Annual Review of Ecology and Systematics, 33, 665-706.

Sanz-Aguilar, A., Manuel Igual, J., Oro, D., Genovart, M. \& Tavecchia, G. (2016) Estimating recruitment and survival in partially monitored populations. Journal of Applied Ecology, 53, 73-82.

Saunders, S.P., Cuthbert, F.J. \& Zipkin, E.F. (2018) Evaluating population viability and efficacy of conservation management using integrated population models. Journal of Applied Ecology, 55, 1380-1392.

Schaub, M. \& Abadi, F. (2011) Integrated population models: a novel analysis framework for deeper insights into population dynamics. Journal of Ornithology, 152, 227-237.

Scheuerell, M.D. (2016) An explicit solution for calculating optimum spawning stock size from Ricker's stock recruitment model. Peerj, 4, e1623.

Scheuerell, M.D., Hilborn, R., Ruckelshaus, M.H., Bartz, K.K., Lagueux, K., Haas, A. \& Rawson, K. (2006) The Shiraz model: a tool for incorporating anthropogenic effects and fish-habitat relationships in conservation planning. Canadian Journal of Fisheries and Aquatic Sciences, 63, 1596-1607. 
539 Schindler, D.E. \& Hilborn, R. (2015) Prediction, precaution, and policy under global change. Science, 347, 953-954.

541 Su, Z.M. \& Peterman, R.M. (2012) Performance of a Bayesian state-space model of semelparous species for stock-recruitment data subject to measurement error. Ecological Modelling, 224, 76-89.

544 Thorson, J.T., Scheuerell, M.D., Buhle, E.R. \& Copeland, T. (2013) Spatial diversity buffers temporal variability in early juvenile survival for an endangered Pacific salmon. Journal of Animal Ecology, 83, 157-167.

Thorson, J.T., Skaug, H.J., Kristensen, K., Shelton, A.O., Ward, E.J., Harms, J.H. \& Benante,

Vehtari, A., Gabry, J., Yao, Y. \& Gelman, A. (2019) loo: Efficient leave-one-out crossvalidation and WAIC for Bayesian models. R package version 2.1.0. J.A. (2015) The importance of spatial models for estimating the strength of density dependence. Ecology, 96, 1202-1212. one-out cross-validation and WAIC. Statistics and Computing, 27, 1413-1432.

Wade, A.A., Beechie, T.J., Fleishman, E., Mantua, N.J., Wu, H., Kimball, J.S., Stoms, D.M. \& Stanford, J.A. (2013) Steelhead vulnerability to climate change in the Pacific Northwest. Journal of Applied Ecology, 50, 1093-1104.

Waples, R.S. (1991) Pacific salmon, Oncorhynchus spp., and the definition of "species" under the Endangered Species Act. US National Marine Fisheries Service Marine Fisheries Review, 53, 11-22. 
560

561

562

563

564

565

566

567

568

569

570

571

572

573

574

575

576

577

578

579

580

581

582

Ward, E.J., Anderson, J.H., Beechie, T.J., Pess, G.R. \& Ford, M.J. (2015) Increasing hydrologic variability threatens depleted anadromous fish populations. Global Change Biology, 21, 2500-2509.

Ward, E.J., Holmes, E.E., Thorson, J.T. \& Collen, B. (2014) Complexity is costly: a metaanalysis of parametric and non-parametric methods for short-term population forecasting. Oikos, 123, 652-661.

Weber, E.D. \& Fausch, K.D. (2003) Interactions between hatchery and wild salmonids in streams: differences in biology and evidence for competition. Canadian Journal of Fisheries and Aquatic Sciences, 60, 1018-1036.

Winship, A.J., O'Farrell, M.R. \& Mohr, M.S. (2014) Fishery and hatchery effects on an endangered salmon population with low productivity. Transactions of the American Fisheries Society, 143, 957-971.

Yen, J.D.L., Tonkin, Z., Lyon, J., Koster, W., Kitchingman, A., Stamation, K. \& Vesk, P.A. (2019) Integrating Multiple Data Types to Connect Ecological Theory and Data Among Levels. Frontiers in Ecology and Evolution, 7.

Zabel, R.W. \& Levin, P.S. (2002) Simple assumptions on age composition lead to erroneous conclusions on the nature of density dependence in age-structured populations. Oecologia, 133, 349-355.

Zabel, R.W., Scheuerell, M.D., McClure, M.M. \& Williams, J.G. (2006) The interplay between climate variability and density dependence in the population viability of Chinook salmon. Conservation Biology, 20, 190-200.

Zipkin, E.F. \& Saunders, S.P. (2018) Synthesizing multiple data types for biological conservation using integrated population models. Biological Conservation, 217, 240-250. 


\section{FIGURES}
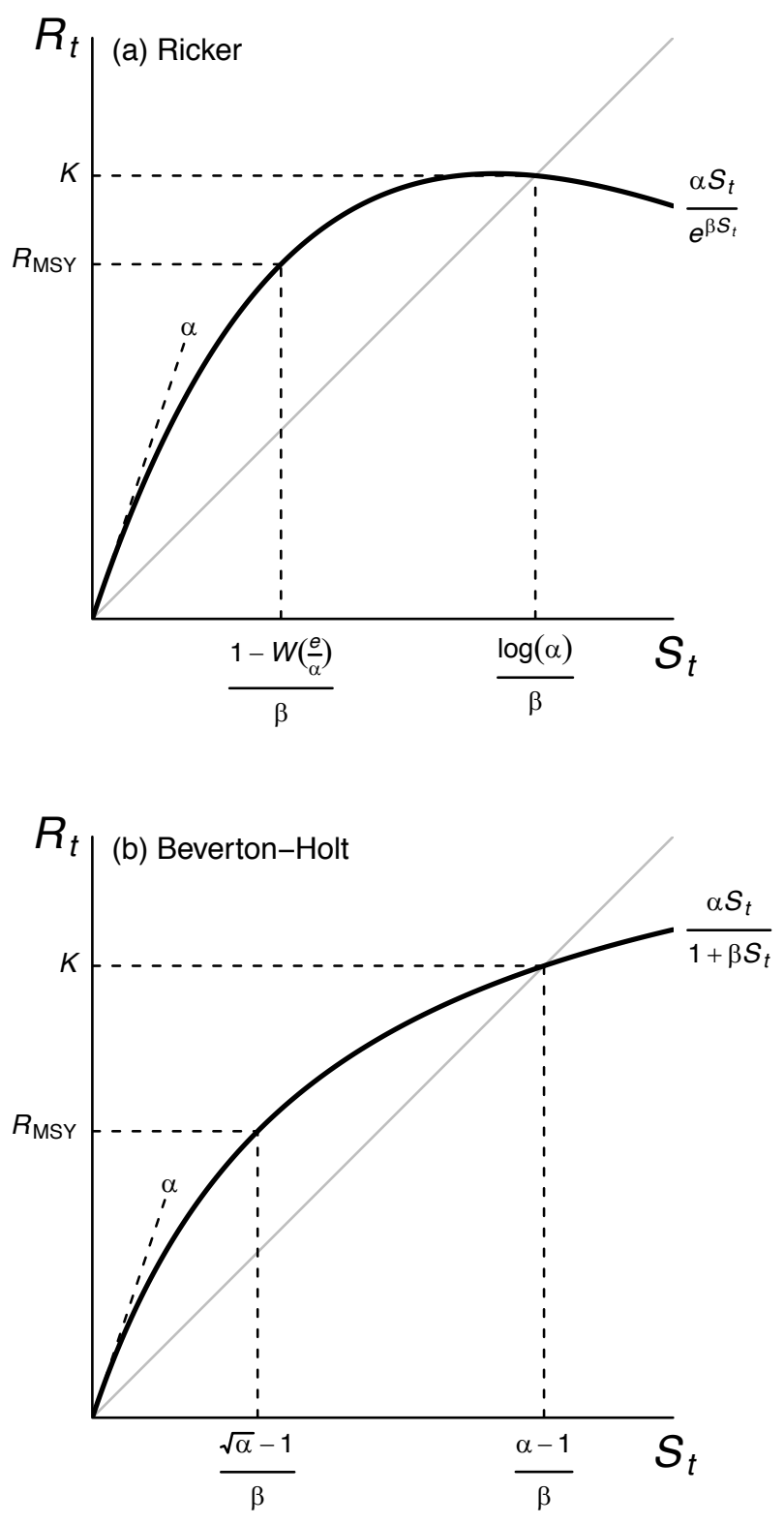

Figure 1. Deterministic forms of the (a) Ricker and (b) Beverton-Holt models used in the analyses (thick lines), including equations for carrying capacity $(K)$ and the number of recruits corresponding to the maximum sustained yield $\left(R_{\mathrm{MSY}}\right)$. The parameter $\alpha$ defines the slope at the origin, the constant $e$ is Euler's number, and $W(\cdot)$ is the Lambert function (see Scheuerell 2016 for details). The gray line is where $R_{t}=S_{t}$. 


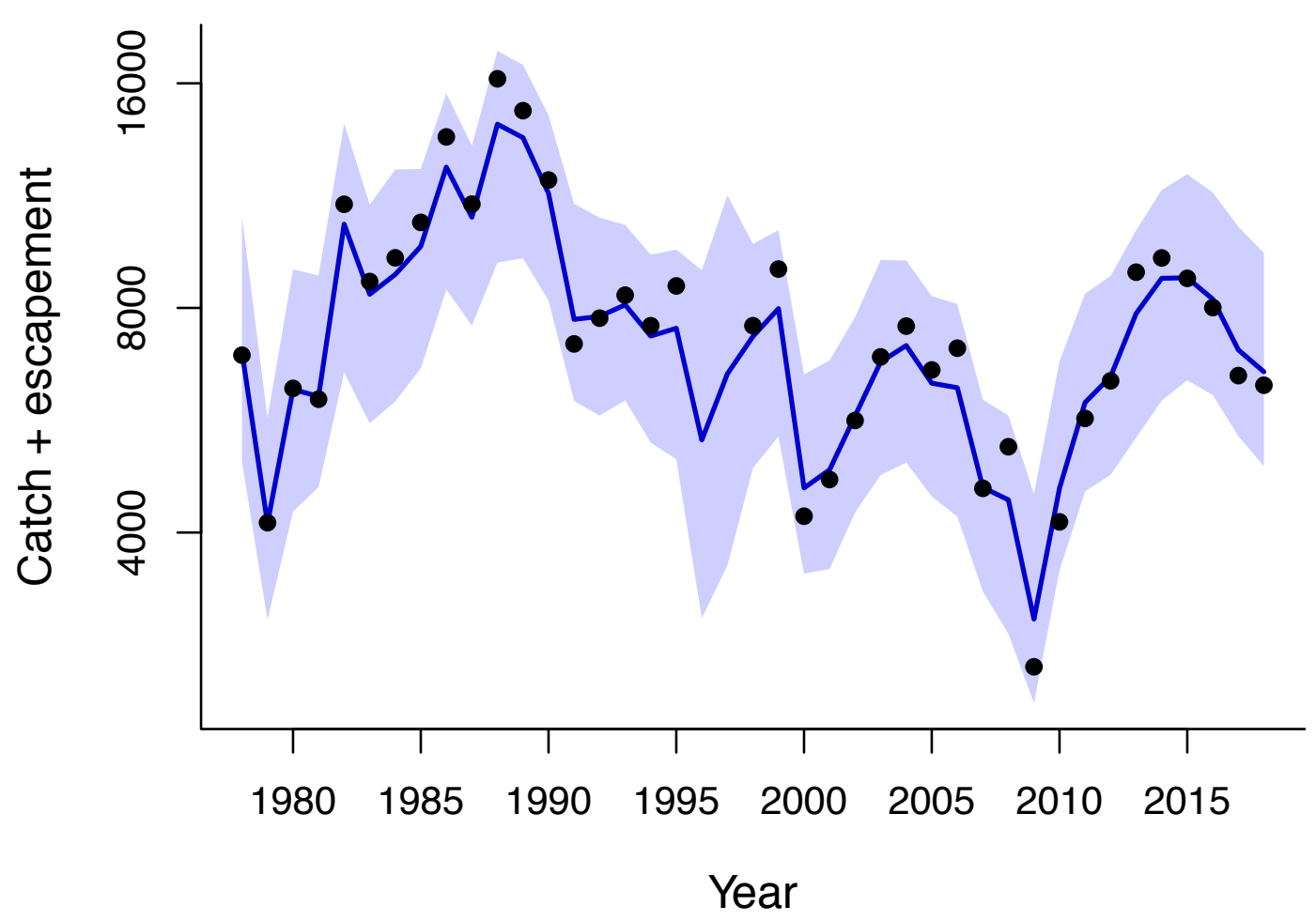

Figure 2. Time series of the estimated total population size (catch plus the adults that escaped to spawn). The observed data are the points; the solid line is the median estimate and the shaded region indicates the $95 \%$ credible interval. 

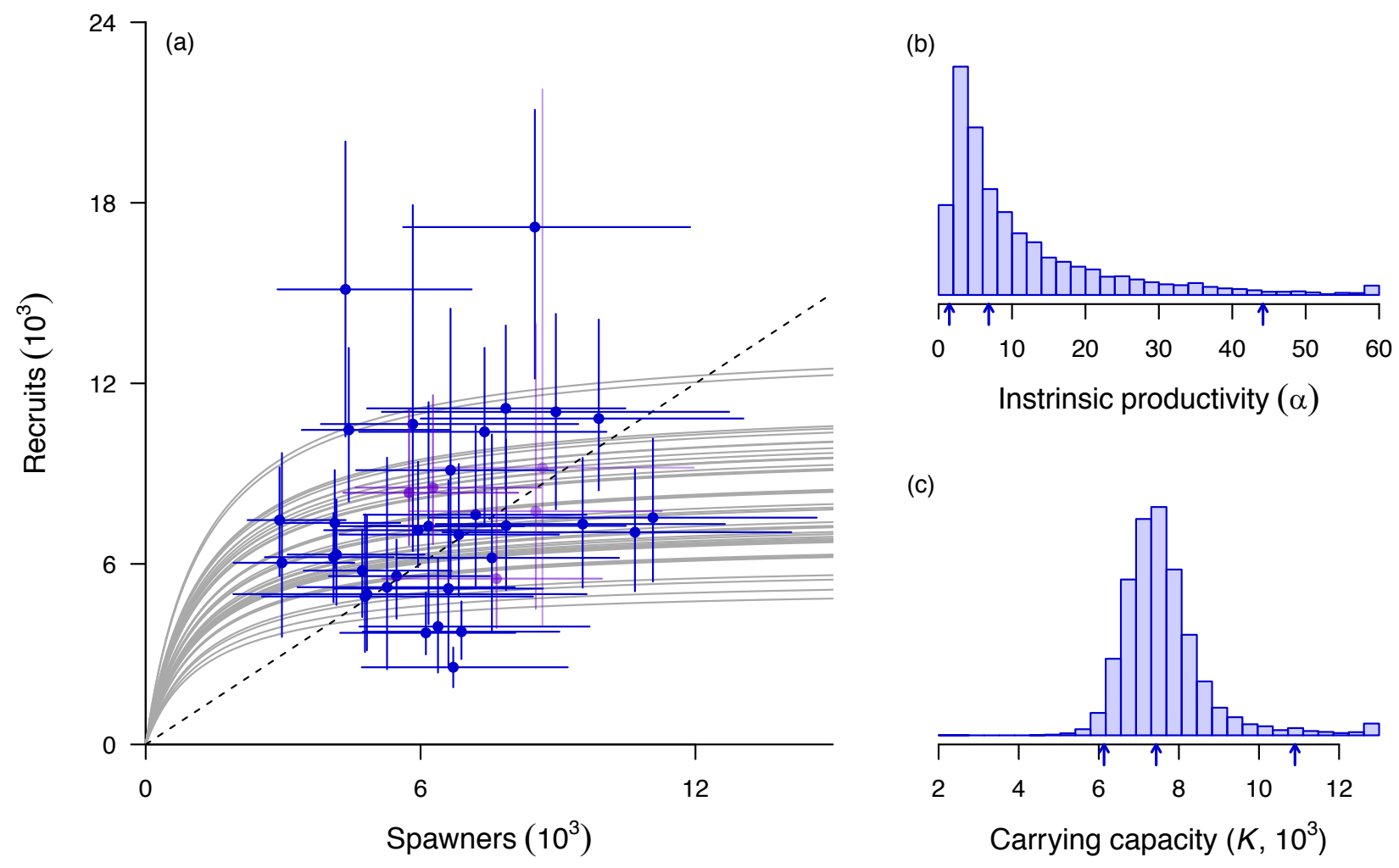

Figure 3. Relationship between the number of spawning adults and their subsequent surviving offspring (recruits), assuming mean values for all covariates (a); and the estimated posterior distributions for the intrinsic productivity (b) and carrying capacity (c). Points in (a) are medians of the posterior estimates; error bars indicate the $95 \%$ credible intervals. Blue points are for estimates with complete broods; purple points are for the most recent years with incomplete broods. Gray lines show the median relationship for each of the 41 years in the time series based on annual model estimates of productivity. Note that for plotting purposes only in (b) and (c), the density in the largest bin for each parameter contains counts for all values greater than or equal to it. Vertical arrows under the x-axes in (b) and (c) indicate the $2.5^{\text {th }}, 50^{\text {th }}$, and $97.5^{\text {th }}$ percentiles. 

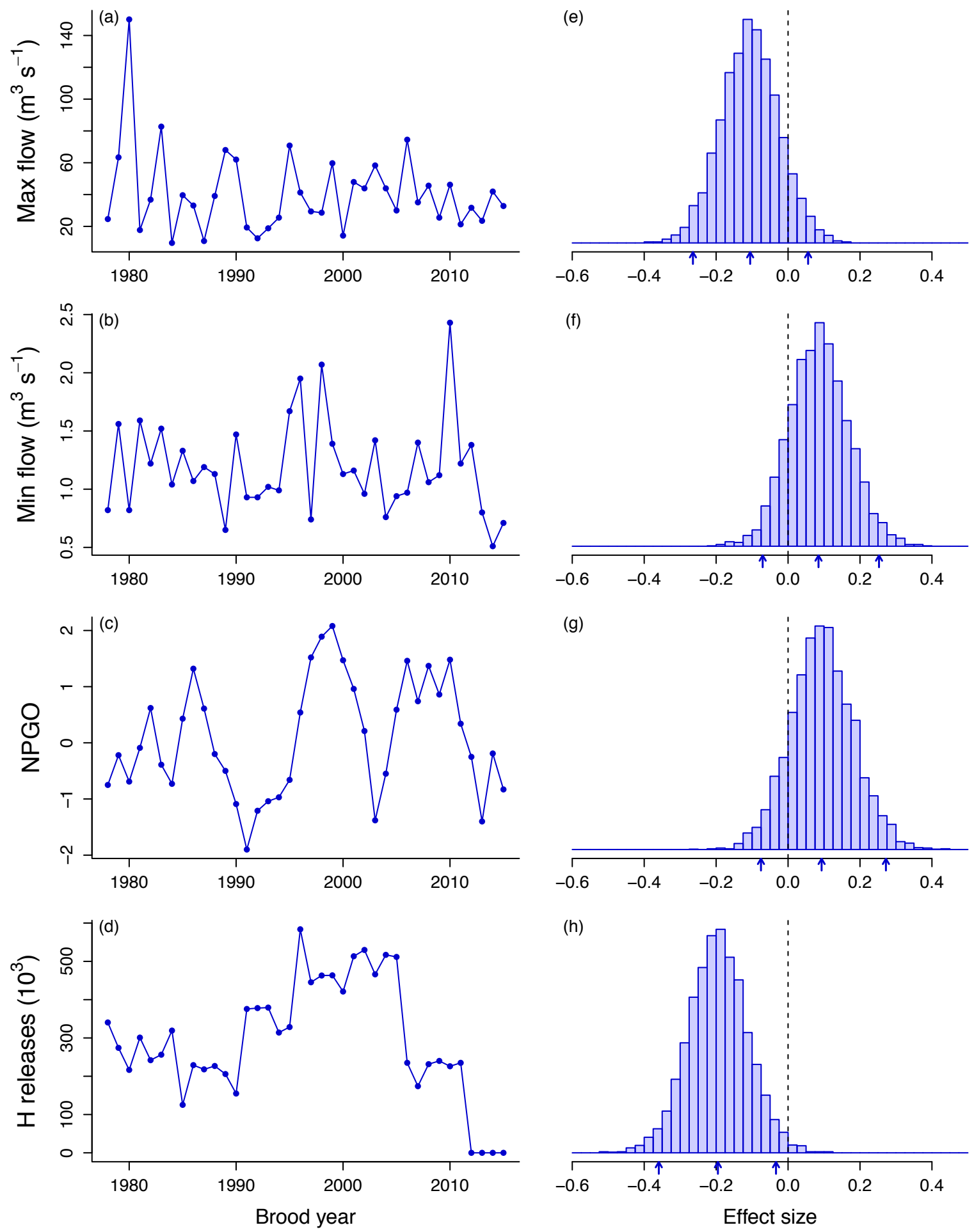

Figure 4. Time series of the environmental covariates used in the model (a-d), and their standardized effects on population productivity (e-g). Small arrows under histograms denote the $2.5^{\text {th }}, 50^{\text {th }}$, and $97.5^{\text {th }}$ percentiles of the posterior distribution. 


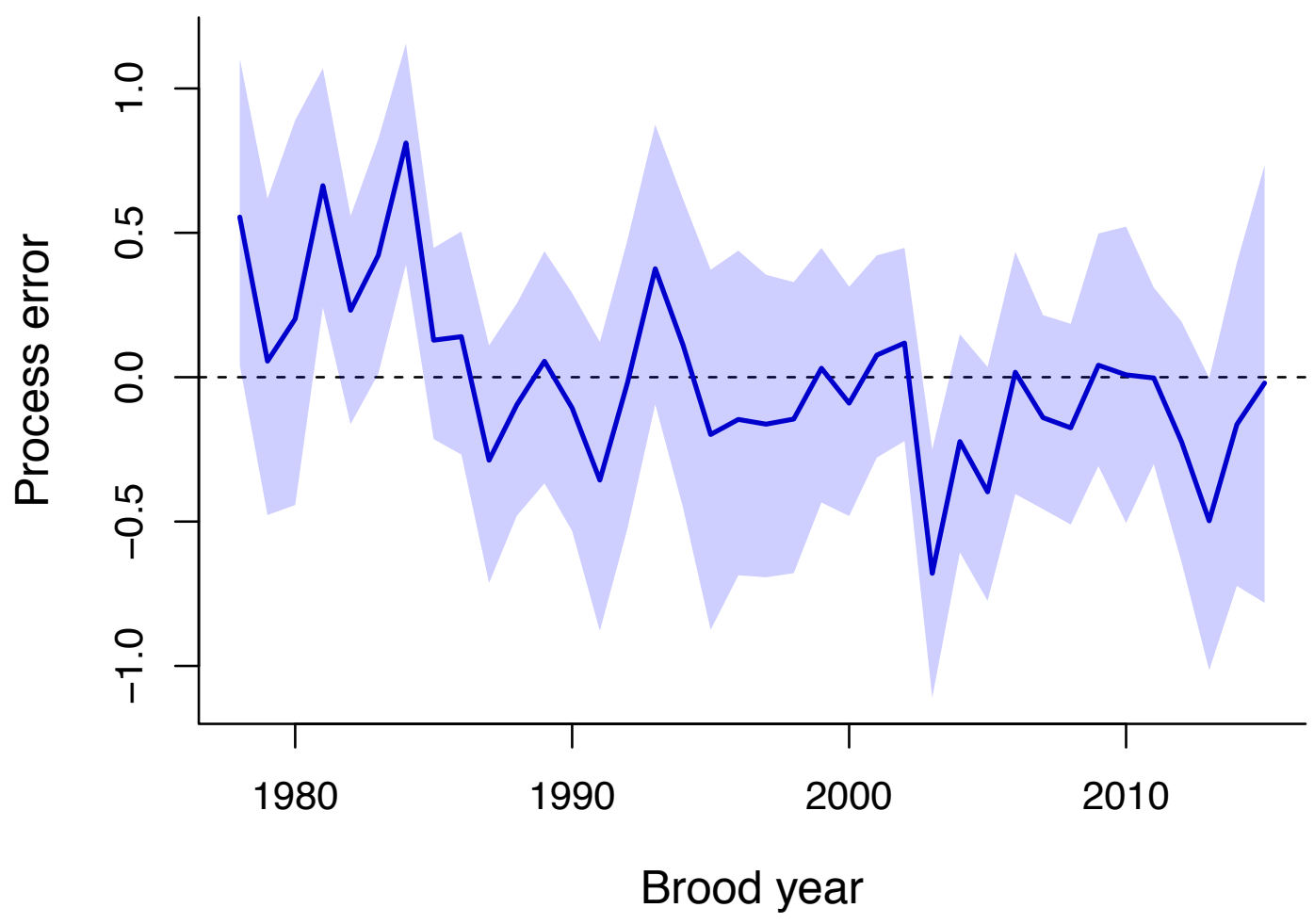

Figure 5. Time series of the estimated process errors, which represent the population's productivity after accounting for the effects of density dependence and environmental covariates. The solid line is the median estimate and the shaded region indicates the $95 \%$ credible interval. 

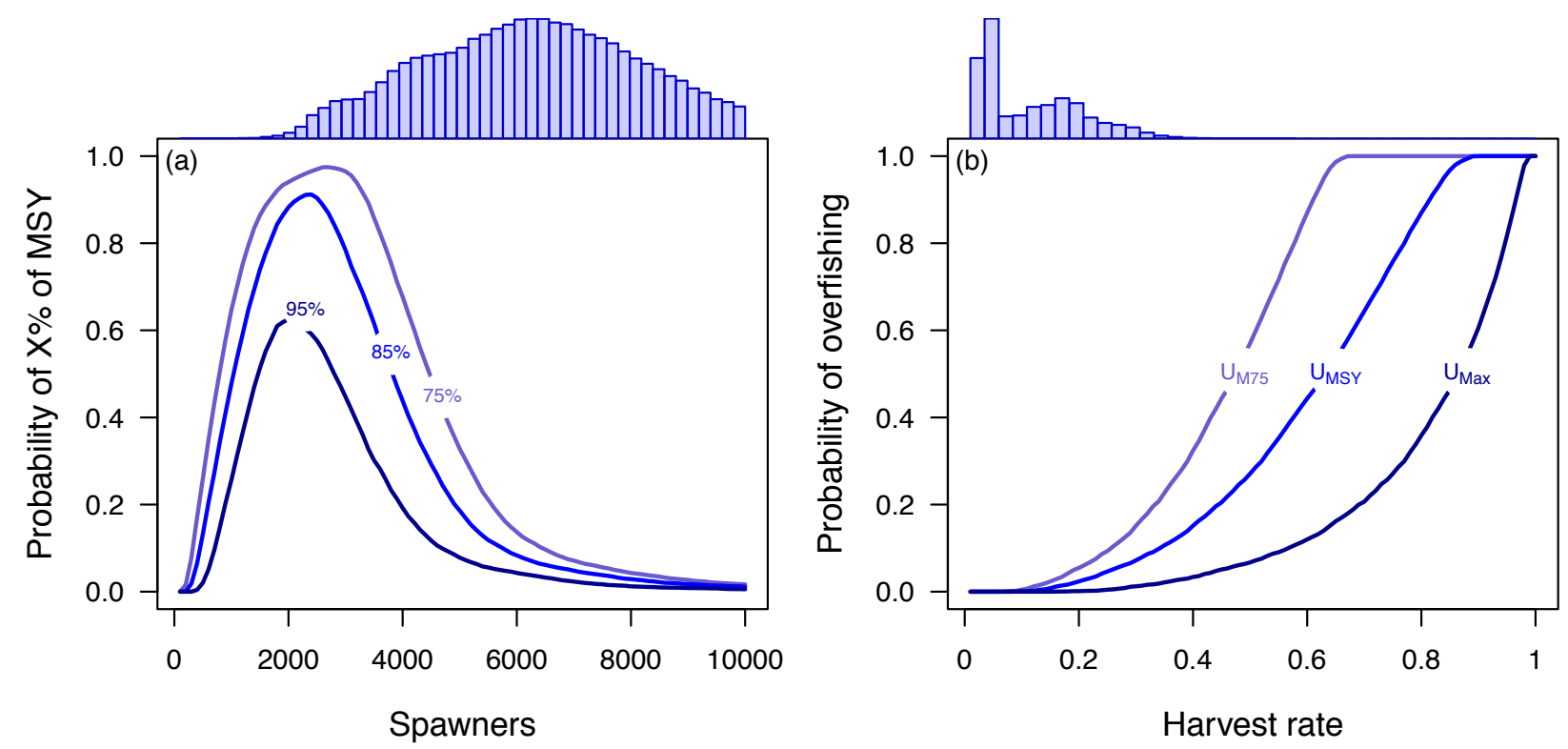

Figure 6. Plots of (a) the probability that a given number of spawners produces average yields achieving $95 \%, 85 \%$, or $75 \%$ of the estimated maximum sustainable yield (MSY); and (b) the cumulative probability of overfishing the population, based on harvest rates equal to those at $75 \%$ of MSY, at MSY, and at the maximum per recruit. The histograms above (a) and (b) are distributions of the posterior estimates for the number of spawners and harvest rates, respectively; the histogram in (a) has been truncated at $10^{4}$. 
bioRxiv preprint doi: https://doi.org/10.1101/734996; this version posted August 15,2019 . The copyright holder for this preprint (which was not certified by peer review) is the author/funder, who has granted bioRxiv a license to display the preprint in perpetuity. It is made available under aCC-BY-NC-ND 4.0 International license.

\section{SUPPORTING INFORMATION}

Additional Supporting Information may be found in the online version of this article:

Appendix S1. Instructions for retrieving and archiving the environmental covariates.

Appendix S2. Model definitions, model fitting, and model evaluation.

Appendix S3. Steps to recreate figures from main text. 